\title{
Mi colegio de Luis Antonio de Villena y la inminencia de la injuria
}

\author{
Sergio Coto-Rivel \\ Université de Nantes, France
}

\begin{abstract}
Resumen
El presente artículo se centra sobre la escritura íntima del escritor español Luis Antonio de Villena, particularmente sobre su libro de memorias Mi colegio, publicado en 2006. De esta manera, el artículo está construido a partir de dos preguntas básicas: en primer lugar ¿cuáles son las estrategias discursivas que caracterizan la escritura de memorias en el texto seleccionado? Y en segundo lugar, ¿de qué manera la injuria como acto discursivo se presenta como un hilo conductor en la narración de la memoria del autor? Las respuestas a estas interrogantes serán desarrolladas a partir del análisis textual de Mi colegio, la comparación con otros textos autobiográficos del autor y el apoyo de una serie de elementos teóricos que fundamentan nuestras hipótesis.
\end{abstract}

Palabras claves: literatura española, memorias, sexualidad, Luis Antonio de Villena, siglo XX

\begin{abstract}
This article focuses on the intimate writing of the Spanish author Luis Antonio de Villena, particularly on his memoir book Mi colegio, published in 2006. This way, the article is built from two basic questions: first, which are the discursive strategies that characterize the memoir writing in the selected text? And second, in what way the insult as a discursive act is presented as a conductive thread in the memoir writing of the author? The answers to these questions will be developed from the textual analysis of $\mathrm{Mi}$ colegio, the comparison with other autobiographical texts of the author and the support of a series of theoretical elements that base our hypothesis.
\end{abstract}

Key words: Spanish literature, memories, sexuality, Luis Antonio de Villena, $20^{\text {th }}$ Century 


\section{Introducción}

¿A qué recordar?, me digo a veces. Era una España muy cerril y cabruna (Villena, 2006: 51).

$\mathrm{E}$ 1 escritor español contemporáneo Luis Antonio de Villena, además de tener una importante producción poética y narrativa, se ha dedicado también al género autobiográfico, en particular a la escritura memorialística. Es notable dentro de sus libros de carácter autobiográfico, una necesidad de volver sobre la época de la infancia para tratar de exorcizar un pasado doloroso ligado a la necesidad de normalización, a la discriminación y a la injuria. A pesar de haberse formado dentro de un marco de clase privilegiada, el autor señala constantemente una condición de paria causada por sus preferencias sexuales. El caso de $M i$ colegio, libro publicado en 2006, retoma estos aspectos tratados de manera diferente en otros de sus libros que mencionaremos más adelante. Sin embargo, este último pone un énfasis especial en la construcción identitaria marginal y el dolor de la ofensa. A continuación, analizaremos no solamente este aspecto determinante de la construcción narrativa, sino también los caracteres formales de la escritura de memorias en el texto.

La época que comprende la narración de Mi colegio se sitúa entre los años 1962 y 1968, los cuales corresponden con el tiempo en el que el protagonista pasa en el colegio Nuestra Señora del Pilar en Madrid ${ }^{1}$. Este colegio poseía un gran prestigio para ese momento ya que ahí eran enviados los hijos de las familias acomodadas de la capital, razón por la cual la madre del protagonista decide inscribirlo ahí luego de la muerte del padre, con el deseo de que reciba una mejor educación en un instituto de renombre. El traslado se da en segundo año de bachillerato, luego de haber cursado el primero en un colegio público de la calle Serrano.

El libro se encuentra dividido en catorce capítulos cortos, los cuales desarrollan distintos temas específicos sobre la vida del colegio, por lo tanto no hay necesariamente un orden cronológico en la organización de los hechos narrados, sino más bien una organización temática.

\section{Estructura del relato}

La narración inicia con una llamada telefónica de un ex compañero del colegio para invitar al protagonista a un Te Deum por la celebración de las bodas de plata de su generación. El protagonista se niega con la explicación de que él ya no tiene nada que ver con esa gente y esos recuerdos. Este hecho es el punto de partida de la narración a fin de explicar en cierta medida su fuerte rechazo a la evocación de dicha institución de enseñanza.

Desde el inicio del texto, el narrador trata de cuestionarse de qué exactamente se tratará el libro que está empezando a escribir. Podemos ver una reflexión en torno al proceso de escritura de forma simultánea, ya que el autor 
identifica a partir de la rememoración una variedad de temas posibles, como por ejemplo el machismo, la educación nacional-católica o la injusticia de los adolescentes. Sin embargo, se orientará especialmente por su visión de una posición marginal o de paria dentro de una institución que forma las élites de la nación.

Los diferentes capítulos se centran en aspectos de la vida institucional durante los años sesentas y particularmente en la experiencia vivida por el propio autor. La educación religiosa de la época estaba íntimamente ligada a las ideas de patria que se consideraban necesarias en la formación de los niños, por lo cual era difícil hacer una separación entre ambas. A continuación se narra una serie de hechos considerados como la parte central del texto y que tienen que ver con la manera en que el protagonista tuvo que lidiar con el insulto y sus compañeros, quienes veían en él una rara avis. Por lo tanto, era objeto de burla, ya fuera por sus excentricidades, comportamientos afeminados o aniñados y timidez, principalmente. De esta forma, el ambiente sumamente machista del colegio y del contexto general permitía que se diera impunemente todo tipo de atropellos.

\section{Rasgos de la escritura autobiográfica}

Mi colegio es el texto autobiográfico más reciente de Luis Antonio de Villena y se organiza como una manera de regresar a la época del bachillerato en un intento de desligarse del dolor causado por los compañeros y sus insultos. Este propósito autobiográfico se ve como una constante dentro de los textos de Villena, ya que el tema se hace recurrente y aparece con variaciones a través de su obra. Esto lo podemos ver al comparar Mi colegio con otros dos libros de carácter autobiográfico del autor: Ante el espejo (1982) y Patria y sexo (2004)², ya que en ellos se retrata, en mayor o menor medida, la época comprendida entre los diez y veinte años, con especial énfasis en un momento característico que parece haber dejado una huella particular: los diez años. Esto se ve primero en Ante el espejo cuando se narra el viaje al campamento de la sierra y la entrada al colegio religioso, aunque de forma general y muy matizada con la ficción. Dichos acontecimientos básicos de los diez años se repiten luego en Patria y sexo, en la narración del campamento en el capítulo "Filos del alba", de forma ya mucho más extensa, y posteriormente la entrada al colegio Nuestra Señora del Pilar, narrada en Mi colegio.

Desde el primer texto autobiográfico hay una necesidad imperiosa de volver sobre la infancia para realizar un acto simbólico de desprendimiento de esos años. Sin embargo, este acto nunca se realiza del todo, ya que se vuelve a tratar en los dos libros de memorias siguientes, veintidós y veinticuatro años después. En la nota final que aparece en Mi colegio se confirma esta situación, ya que el autor manifiesta que "siempre ha querido huir de la infancia y de la patria" (Villena, 2006: 159), aunque después afirma que la huida nunca culmina. Esta premisa es muy importante a la hora de iniciar una lectura de las características del género autobiográfico en el texto de Villena, debido a la vinculación evidente 
que hay con los otros textos publicados anteriormente y que han tratado de llegar a puntos en común desde caminos diferentes, en donde la principal variación ha sido la perspectiva utilizada.

\section{Caracteres estructurales y formales}

Mi colegio tiene un subtítulo muy significativo: "Esplendor y tormento de un escolar adolescente", en el cual se empiezan a establecer relaciones con las otras pistas que los elementos intertextuales ofrecen. Primeramente, los de carácter más visual: la edición de Península (única del texto hasta ahora) incluye en la portada la fotografía del autor a la edad de diez o doce años aproximadamente y la de una de las fachadas del colegio Nuestra Señora del Pilar, elementos que constituyen referencias importantes al ubicar el texto en un espacio geográfico-temporal y en un espacio autobiográfico. De esta manera se implica que es precisamente la vida del autor a la que hace referencia el subtítulo del tormento adolescente.

La narración se encuentra precedida por un epígrafe que corresponde al prefacio que Simone de Beauvoir escribió para la primera parte de la triada autobiográfica ${ }^{3}$ de la escritora francesa Violette Leduc llamada La Bâtarde, cuyo texto es el siguiente: "Tout écrivain qui se raconte aspire à la sincérité: chacun à la sienne qui ne ressemble à aucune autre". Así como originalmente la frase de Beauvoir tenía la finalidad de orientar la lectura del texto de Leduc hacia un sentido autobiográfico, recalcando la sinceridad particular de la escritora, para este caso como epígrafe a Mi colegio posee un carácter muy similar, por medio del cual se señala la diversidad en la forma de contar la propia vida. Esto corresponde con la parcialidad del punto de vista de cada uno, que parte de la idea de una sinceridad propia y no como idea universal. Este hecho es básico a la hora de enfrentarse a la lectura de un texto autobiográfico, en el cual se espera que haya verdad y referencias claras, de modo que el epígrafe rescata la posibilidad de invención, interpretación y parcialidad.

El otro paratexto significativo es la nota final, la cual, como es costumbre en Villena, da cuenta del proceso de escritura del texto al ubicarlo en un momento específico del tiempo. Además explica las motivaciones de la escritura autobiográfica para este caso, sin que estas difieran mucho de los casos anteriores:

Escribí este libro de impresiones recortadas, entre diciembre de 2004 y el primero de junio de 2005. Después de todo, yo, que he querido huir de la infancia y de la patria, a menudo sigo teniendo esa sensación tan benigna cuanto atormentadora. ¿Cómo ser, si no? Jirones, pues, de ese desgarrado dobladillo. Stendhal agregó: Grand Dieu! Pourquoi suis-je moi? [...] La respuesta casi nunca culmina, la huida tampoco. (Villena, 2006: 159)

La principal justificación que se encuentra en la cita anterior para volver sobre los acontecimientos vividos en la infancia se basa en una necesidad de 
desprenderse de ella. Por esto el texto agrega una perspectiva pormenorizada de las implicaciones que tiene la injuria para un niño de edad escolar en contra de su identidad. Para reafirmar esta necesidad de volver sobre sí mismo en un texto íntimo, Villena retoma la cita de Stendhal ${ }^{4}$ que ya había utilizado en Ante el espejo, como la posición del sujeto ante sí mismo y su necesidad de contarse. Como se ha visto, estos elementos externos que van resignificando el texto son determinantes a la hora de presentarse como escritura autobiográfica y para este caso, como el anterior, se acerca mucho más a las memorias como subgénero debido al carácter parcial de una época y un contexto específicos que se pretende narrar, limitándose así a los hechos más relevantes en torno a un tema.

\section{Estructura narrativa y memoria}

El estilo narrativo en $M i$ colegio es muy similar al que se encuentra en Patria y sexo. Ambos proyectos autobiográficos están construidos con base en un mismo principio organizador de la memoria a partir de cuadros o temas específicos (además es necesario recalcar que ambos tienen una gran cercanía en la fecha de su escritura y publicación — dos años de diferencia- y sus ejes temáticos resultan similares). De este modo se puede observar una gran naturalidad a la hora de exponer las situaciones, sin preocuparse por la exactitud de estas. Así entonces el narrador puede dudar de sus afirmaciones, contrastarlas o reconocer la inexactitud de algunas de ellas, precisamente porque resalta constantemente las trampas que deja la memoria.

En las siguientes citas se constata esta naturalidad que se le intenta dar al texto por medio de una introducción fluida y despreocupada de los datos, al aludir la confianza en la traicionera memoria, más que el resultado de una investigación rigurosa: "Los tres datos que aquí van son fruto de un impredecible azar. En un viejo e inutilizado misal - aún con su parte en latín - he hallado una de aquellas estampas piadosas con su oración correspondiente" (Villena, 2006: 12). "No sé con exactitud en qué año se construyó o inauguró el colegio de El Pilar, pero supongo que hacia 1890, cuando aquel barrio comenzó realmente a florecer... La fecha exacta - muy cercana - tampoco importa" (Villena, 2006: 15). "No recuerdo a estas alturas la letra al completo, y me he propuesto (a fuer de natural) fiarme únicamente de la memoria" (Villena, 2006: 37).

Las motivaciones de la esritura autobiográfica pueden ser sumamente variadas y muchas veces no necesariamente identificables ${ }^{5}$. Puertas Moya (2004: 135) propone una clasificación de las motivaciones por la escritura íntima, y entre ellas una de las más sobresalientes es la búsqueda de una identidad que puede conducir a la autojustificación o autovaloración. En el caso de Mi colegio se puede observar que esta última motivación es la más evidente en su producción autobiográfica, ya que hay una constante necesidad de volver a la infancia para tratar de justificar o explicar una identidad en construcción, a partir de la aceptación de una condición marginal y sus formas de defenderse de la injuria. 
Por otro lado, el recuento que se hace en Mi colegio de las memorias infantiles y juveniles está orientado a la reconstrucción de un espacio de formación. Dicho espacio representa en cierta forma la época que se vivía en esos años desde una óptica infantil, por lo que no intenta ser exhaustivo en la descripción de un contexto íntimo más detallado en los acontecimientos fuera del tema básico, que es el desciframiento del proceso de construcción de la identidad (marginal) en el espacio educativo.

\section{Caracteres semánticos}

La referencialidad como carácter semántico básico de Mi colegio implica que la triada de escritor-narrador-protagonista es fácilmente identificable. Precisamente por la necesidad ante la que se halla el autor de evidenciar aún más el espacio desde el que se narra como parte del universo de las memorias. Es decir que el presente de la narración se identifica mucho más con el autor, señalando así una serie de características que lo ubican en un momento específico de su vida.

Ejemplos de lo anterior se encuentran en los capítulos dedicados a personajes reconocidos del país como José María Aznar o Fernando Savater, ya que la narración no se centra en el periodo comprendido entre 1962 y 1968. En estos casos se va más lejos al tratar de explicar la vinculación entre dichos personajes y la época colegial. Ahora bien, estas referencias reconstruyen de cierta forma la vida del autor más allá del marco temporal propuesto en un principio:

Aunque hoy me resulte un hombre antipático y de aires despóticos, aunque crea que ha hecho mucho daño a la derecha española ayudándola a volverse más dura, y aunque vea - con horror-que pretende ser uno de los líderes y hasta ideólogos de esa corriente paleoconservadora [...] debo confesar que el primer día que conocí a José María Aznar y almorcé con él, me cayó bien. (Villena, 2006: 61)

En la cita anterior se ve una parte de las opiniones que expresa el autor sobre José María Aznar, a partir de un encuentro ocurrido en el otoño de 1995. De tal manera, la referencia al encuentro con intenciones políticas del entonces candidato a la presidencia, lleva al recuerdo del colegio. El procedimiento se da por tanto a la inversa de los otros capítulos. Evidentemente este tipo de estrategia de narración colabora de una forma particular dentro del estilo con el que han sido estructuradas las dos obras autobiográficas anteriormente mencionadas, ya que plantea, en primera instancia, una visión distinta de la forma de acercarse a la memoria. Y segundo, porque configura de modo mucho más claro la referencia entre el autor y el narrador al hablar sin ningún tipo de ocultamiento discursivo desde la voz de Luis Antonio de Villena.

De acuerdo con los caracteres semánticos, el nombre propio es la mediación que se establece entre el pensamiento y los textos, es decir entre el individuo 
y sus relaciones. Si se ponen en relación los textos analizados a la luz de esta afirmación, es posible constatar que hay una evolución en la manera en que el nombre propio se hace presente en el texto. A pesar de que este nunca se expresa directamente, tanto en Patria y sexo como en Mi colegio (especialmente en este último), la fluidez de la narración y la poca preocupación del escritor por crear un discurso literario evidencian mayormente la relación establecida con el autor, con su vida y su palabra.

Puertas Moya (2004: 58) considera que el nombre propio es la única prueba que se puede utilizar para medir la identidad entre el narrador y el protagonista, a pesar de que no es cien por ciento fiable. En Mi colegio se encuentra una gran cantidad de referencias que pueden confirmar esta vinculación con el nombre propio del autor aparecido en la portada. Por ejemplo, los elementos paratextuales ya descritos en el apartado anterior, o los que se hallan dentro de la narración en sí. Así como las referencias que hace el narrador respecto de sí mismo en sus distintas facetas literarias, ya sea como poeta o como crítico:

Es curioso que yo fuera un total novísimo, «ab ovo», sin saberlo, sin haber oído nada todavía de aquella poesía nueva. Y es curioso también que mi primera publicación fuera como crítico literario. Es una tarea que nunca he dejado de hacer, a sabiendas - hoy - de que a un creador no le favorece ser a la par crítico (y menos crítico en periódicos) porque obliga a cambiar los modelos de la mirada y el etiquetaje, algo terrible en un mundo perezoso y comercial como el nuestro. (Villena, 2006: 127)

La cita anterior es uno de los múltiples ejemplos en los que el autor aparece mucho mejor identificado en $\mathrm{Mi}$ colegio que en los otros textos de carácter autobiográfico de Villena. Para este caso hay una constante identificación del narrador con el autor a partir de elementos extratextuales, por lo que es posible afirmar que hay una evolución de la escritura memorialística de Luis Antonio de Villena, desde un alto grado a un menor grado de ficcionalización, en donde no se construye un alter ego que diferencie el nombre del autor y del protagonista y donde la figura del narrador se iguala a la del autor.

\section{El espacio íntimo}

Después, cuando caí herido en la cuenta del horror que había padecido, de la víctima que fui, en silencio y sin ayuda por supuesto he llenado repetidamente de maldiciones a mis verdugos. (Villena, 2006: 155)

La construcción del espacio íntimo en el texto autobiográfico puede pensarse en principio redundante, ya que típicamente se ha considerado que toda escritura del yo - en especial con tintes confesionales- está constituida desde lo íntimo, como un espacio al que se puede acceder únicamente mediante la 
introspección y no desde la voz de otros. De igual manera, el espacio íntimo y sus representaciones son muy variados y dependen tanto de la memoria como de los olvidos.

Puertas Moya (2004: 80) señala que es posible acceder a la intimidad por medio de sucesivos e interminables acercamientos, los cuales, de forma paulatina, revelan y encubren, disfrazan y disimulan la verdad del autobiógrafo. Además, hace una importante aclaración respecto del intimismo, al señalar que no es el último reducto de la literatura autobiográfica, sino una manera de llevar al punto central del texto el espacio de lo íntimo, y este entendido como uno de los caracteres semánticos de este tipo de escritura.

En el caso del texto de Villena, es posible encontrar distintos grados de representación de lo íntimo, gracias a su división en apartados o capítulos independientes que van tratando de conformar una visión más generalizada del tema (diversos ejemplos aparecen en capítulos que se centran en la descripción del ambiente colegial, compañeros específicos y situaciones particulares, en contraste con los que se encargan de una mayor introspección relativa al efecto dañino del grupo sobre el protagonista). Más allá de esto, el carácter memorialístico del texto hace que se dé un mayor intento de sobrepasar las divagaciones meramente introspectivas para abarcar también las implicaciones de los otros que lo rodean en un juego de poderes y ansias de estructurar vínculos "aceptables". Por lo cual, al ubicar el texto dentro de dicho tipo de producción, hay un mayor interés en poner en contexto la discriminación sufrida durante la época colegial y tratar de explicar cómo es que se produce este tipo de discursos sociales y en qué medida pueden llegar a afectar la personalidad de un sujeto.

En el epígrafe anterior es posible notar la posición de víctima en la que se coloca el autor en algunos de los capítulos, lo cual pone un importante énfasis en la carga negativa que traía el colegio en sus recuerdos. Así, la parte más introspectiva del texto se basa en el dolor que producía el rechazo de los compañeros y al mismo tiempo pone en evidencia un intento por curar esas heridas profundas en el proceso de escritura de la memoria.

\section{La descalificación en la palabra}

Nunca el fuerte es más fuerte ni el débil más débil, que cuando el normal se abate sobre el distinto, sin miedo a un dominio insultante que llega a percibir como eclesial, obligado y mesiánico. (Villena, 2006: 61)

Uno de los temas más desarrollados en Mi colegio, y que lo diferencia de los otros dos textos autobiográficos del autor, es precisamente la manera de centrarse en el carácter performativo del discurso de la ofensa y el poder que este tiene en la construcción de las identidades de género. De acuerdo con Butler (2001), el género se construye de manera performativa, a partir de la repetición constante de una serie de enunciados que van dando forma a las características esperables, y al mismo tiempo reprochables de lo que socialmente se entiende como género. 
Estas características han sido percibidas desde la norma de la sociedad patriarcal y heterosexista, en la conformación de un esquema dual y antagónico en lo masculino y lo femenino, apoyado por valoraciones dicotómicas como activo/pasivo, fuerte/débil, razón /emoción, etc.

Ahora bien, si se piensa en una subversión del esquema tradicional, desde estas consideraciones, es posible identificarla en el valor que implican estos enunciados antagónicos básicos y repetitivos de una identidad realizable socialmente. En la ruptura emergen "los raros", es decir quienes se salen de estas configuraciones típicas y tradicionalmente aceptadas. De igual forma, el efecto contrario, que implica un intento de regularización, tiene un arma fuerte desde el lenguaje, la cual Eribon (2001) denomina, "la injuria".

La marginalidad se construye en principio desde la palabra, la cual inicia un proceso de exclusión de lo que no considera aceptable dentro de un marco de referencia específico. De este modo, se generan estrategias para desacreditar las características diferenciadoras del otro. Estas aseveraciones en torno al género engloban los enunciados que producen, tanto las imágenes aceptadas socialmente y en una época determinada, como las que no, lo cual conduce inevitablemente a una estructuración vertical del poder entre dominante y dominado. Esto es, quien tiene la palabra y quien es creado por esa palabra. Eribon lo plantea de la siguiente forma: "El dominante, como dice Pierre Bourdieu, es el que consigue imponer la forma en que quiere ser percibido, y el dominado es definido, pensado y hablado por el lenguaje del otro, o el que no logra imponer la percepción que tiene de sí mismo, o ambas cosas" (Eribon, 2001: 108).

\section{Decirse o no decirse}

En el caso particular de la identidad gay vista en el texto de Villena, es posible observar las vinculaciones verticales del lenguaje dominante que han determinado la estructuración de una identidad para el protagonista de $\mathrm{Mi}$ colegio. Uno de los rasgos que aparece constantemente en el texto es la angustia que implica tener que construir un alter ego para tratar de satisfacer, en parte, los requerimientos del grupo y no ser constante objeto de burla. El problema al que se atiene el protagonista es que, a pesar de no asumir su identidad sexual abiertamente durante toda su adolescencia, esto no lo libró del escarnio. De acuerdo con el autor, sus particularidades eran evidentes, como por ejemplo el refugio en la adquisición de conocimiento, el vestir extrovertido, la timidez para vincularse con sus compañeros, los aires aniñados, etc. Ante estas características salidas de la norma homogenizadora, dice el protagonista: "fui en seguida mirado, señalado y sentido y declarado distinto, desde la suprema regla del machismo feroz. Y desde ese mismo instante, y sin mayor juicio o apelación, condenado" (Villena, 2006: 49).

Se presenta en el texto, de esta manera, un cuestionamiento básico que manifiesta implícitamente el protagonista al enfrentarse al rechazo de los demás, entre la necesidad de expresarse de forma natural, como él mismo se siente, o 
crear una especie de escudo protector en una personalidad evasiva y encerrada en sí mismo. A pesar de ser muy consciente de que solamente la palabra lo liberará - asumir su identidad y manifestarla abiertamente - elige continuar el juego de máscaras que lo lleva a un enclaustramiento mayor. Es esto precisamente a lo que Eribon denomina dominación epistemológica:

Es una paradoja insuperable: el gay que decide decirse se expone al comentario irónico o condescendiente y a veces al desaire, y el que decide callarse se coloca en una situación falsa y en todo caso dependiente [...] Está en una situación de dominación "epistemológica», porque tiene entre las manos las condiciones de producción, de circulación y de interpretación de lo que puede decirse de este gay en particular. (Eribon, 2001: 84)

La dominación epistemológica consiste entonces en la apropiación de la palabra por parte del dominante, quien tiene la capacidad de manifestar su opinión e imponerla respecto de los otros que no tienen el derecho de hablar. Para el caso particular del texto, los compañeros de clase, esa "minoría agresiva" como él mismo la llama, son quienes ejercen la capacidad de imponer la norma por medio de la ridiculización de lo alterno. A esta se le suma una "mayoría silenciosa", es decir, la que mira desde el exterior la difamación y no hace nada al respecto, sino que con su silencio aprueba la práctica y permite que se haga natural y cotidiana. Al respecto dice el narrador: "Algunos compañeros, al principio, intentaron defenderme. Luego hicieron como que no veían o como que no pasaba nada o, más llanamente, se habituaron: cosas de niños, expresión nuevamente odiosa en un caso tal" (Villena, 2006: 49).

Aunque no se forme parte del grupo que insulta, si no se reprende la acción o se denuncia, se pasa entonces a formar parte inmediatamente de esa masa dominante que entiende el género y las sexualidades como un solo sistema, establecido en un par complementario y reglamentado. La misma que trata de mantener las diferencias relegadas por medio de una ilusión discursiva de la normalidad. A partir de esta dinámica de control basada en el heterosexismo del patriarcado, se crea la metáfora del "armario" como un espacio significativo en el que se construye un yo diferencial para el enmascaramiento:

El clóset no es más que el producto de complejas relaciones de poder. La única razón para estar en el clóset es protegerse de las formas diversas y virulentas de descalificación que uno sufriría si se conociera públicamente su condición sexual. Quedarse en el clóset, ocultar la homosexualidad, implica también someterse al imperativo social impuesto a los gays por los que no se identifican como gays, que protege a estos no del conocimiento de la homosexualidad de alguien, sino de la necesidad de reconocer la homosexualidad de alguien. Aunque brinde a sus ocupantes una serie de posibilidades, inaccesibles de otra forma, y les dé algunos de los privilegios reservados a los heterosexuales, no es posible pensar al clóset como una experiencia de la libertad. [...]. (Halperin, 2000: 51) 
De acuerdo con la cita de Halperin, se considera el "armario" o closet como un espacio producto de la discriminación, el cual a su vez puede otorgar privilegios - entendidos estos en un sentido muy amplio de la palabra, debido al carácter excluyente que tiene- en la medida en que el sujeto intenta llevar su vida más allá del reconocimiento público de sí mismo. Es necesario también recordar que el periodo contado en el texto corresponde a una etapa en la que los adolescentes empiezan a identificar en su cuerpo y en su personalidad las características del género, las cuales les vienen siendo enseñadas desde un punto de vista tradicional (hay que tener en cuenta el peso del régimen en el que vivía España en los años sesenta, unido a un espacio de enseñanza católica y exaltación de la patria fascista que el narrador se encarga de subrayar). En esta etapa entonces, hay fuertes presiones a reconocerse con el grupo y a demostrar que se merecen los atributos de masculinidad por medio de pruebas iniciáticas y primeras experiencias, llámense estas eróticas, sexuales o amorosas. De manera que el protagonista se enfrenta a un grupo al que no puede pertenecer ni oponerse abiertamente, por lo cual reacciona de maneras distintas, en especial reflejando una pose de intelectual o de filósofo al que no le importa ese tipo de peleas adolescentes, lo cual evidentemente resulta una máscara más. Con base en este proceso, el narrador analiza la manera en que El Pilar incidió en su educación, no solo académicamente, sino también en la conformación de esa identidad desde la marginación, en oposición a la idílica imagen que el colegio representaba de formar a los "mejores estudiantes":

Se supone que en el Pilar recibí la enseñanza y el estilo reservados a la élite del país, pues estaba - y era opinión general y antigua - en el sitio mejor y entre los mejores; pero como yo fui también insultado y ofendido, porque me consideraron distinto, diferente, afeminado - la sexualidad o presunta sexualidad marcaba terriblemente en un territorio tan machista-, recibí también, o me la impusieron, la mirada y el saber de los parias, el punto de vista de los acusados y otros, por lo que salí de entre tantas ojivas y torreoncillos góticos con una visión excepcionalmente doble: sabía lo que era pertenecer a los mejores - con comillas, sin duda-y también a los peores, con otras comillas necesariamente distintas. (Villena, 2006: 17)

En la cita anterior se hace evidente este doble discurso que implica el colegio para el personaje, en el cual se halla un prestigio dado en donde las "mejores familias" de Madrid desean que sus hijos reciban la mejor educación (igual como lo expresa el mismo narrador en el deseo de su madre) y, al mismo tiempo, funciona como escenario de marginación de ciertos estudiantes que se salen de la norma al no cumplir con los requerimientos básicos de la masculinidad adolescente y sus pruebas o ritos iniciáticos. Al pensar la dominación desde el lenguaje, como punto de partida básico de la estructura, resulta muy significativa la frase del narrador presente en la cita: "recibí también, o me la impusieron, la mirada y el saber de los parias", ya que es precisamente esa condición de dejarse describir por la palabra del dominante lo que coloca al 
discriminado en una posición de dominación epistemológica, como se describió anteriormente.

\section{La injuria y el recuerdo}

Me prometí a mí mismo (mucho después, en los días en los que ya supe y la conciencia, al fin, se atrevió a sondear el espejo) que nunca más, nunca, querría saber nada de ese colegio. (Villena, 2006: 9)

El epígrafe con el que se inicia este apartado corresponde precisamente al inicio de Mi colegio, en el que el narrador reconoce un acto performativo del discurso como lo es la eliminación de las imágenes personales del colegio El Pilar por causa del dolor que implican sus recuerdos. Es importante señalar que esta promesa hecha a sí mismo se realiza tiempo después de haber pasado por este lugar y evidentemente posterior a un proceso de reconocimiento y reconstrucción de su identidad de género en la que se asume como natural lo que siempre ha formado parte de lo "antinatural". Además, hay un matiz muy importante y es que la condición necesaria para el reconocimiento propio fue la posición "ante el espejo"; es decir que la introspección como ejercicio fue fundamental para que se pudiera dar una reelaboración de las propias nociones sobre sí mismo y en especial sobre su sexualidad.

No hay que olvidar tampoco que la metáfora del espejo ha sido determinante dentro de los textos autobiográficos de Villena, en la medida en que esta funciona como la representación del hecho mismo de la escritura íntima a partir de un examen de conciencia o introspección. De esta forma, el hecho de situar la confesión al inicio del texto condiciona su lectura también como una posición especular del autor, en la que va a tratar de comprenderse a sí mismo con base en los recuerdos dolorosos de la infancia, los cuales han calado en su forma de construirse el género y la sexualidad.

Los tres textos autobiográficos de Luis Antonio de Villena que se dedican en mayor parte a la infancia y adolescencia tienen en común, en mayor o menor medida, una constante referencia a la crueldad que implican las prácticas de los niños al excluir a quien consideren diferente. Esto se puede decir que es el principal tema de Mi colegio, alrededor del que giran y se organizan los recuerdos. Así, el punto de partida que se da por medio de una llamada telefónica de un excompañero sirve para iniciar el viaje de introspección, el cual implica también un intento más de dejar atrás el dolor causado en un lugar y tiempo específicos. En este sentido, el ejercicio de la escritura del yo, para el caso de Mi colegio, tiene un marcado tinte de ruptura con el pasado. Es decir que se recuerda no por el placer de rememorar un tiempo idílico, sino que, por el contrario, funciona como ejercicio de desprendimiento e intento de comprender de qué manera se tejen las redes de poder que llevan a la construcción de las identidades de género desde el machismo.

Las reflexiones hechas por Eribon (2001) acerca del papel que juega la desacreditación de un comportamiento o práctica a través del lenguaje humillante 
y burlesco, resultan sumamente esclarecedoras sobre la manera en que se estructura el proceso difamatorio. En especial cuando se trata de un momento en la vida del sujeto en el que se están empezando a conformar los puntos de referencia básicos con los que funcionan los arquetipos de masculinidad tradicional. Dice Eribon:

El lenguaje cotidiano (al igual que el lenguaje de las imágenes) está atravesado por relaciones de fuerza, por relaciones sociales (de clase, sexo, edad, raza, etc.), y es en y por el lenguaje (y la imagen) como se ejerce la dominación simbólica es decir la definición - y la imposición- de las percepciones del mundo y de las representaciones sociales legítimas. (Eribon, 2001: 108)

El planteamiento de Eribon explica que el punto central, a partir del cual el gay ha tenido que construir su identidad, ha sido la injuria, entendida esta como un agravio o un ultraje contra alguien, lo cual implica para este contexto una masculinidad menoscabada, denigrada o dudosa. Por esto, Eribon lo resume en que "en el principio era la injuria" referido a la necesidad de configurar la identidad desde la marginalidad y el oprobio, y posteriormente teniendo que resignificar ese espacio desacreditado para otorgarle nuevos referentes. Este proceso se fundamenta en el hecho de que es por medio del lenguaje que se arman las estructuras verticales de diferencia social, de sexo, etc., y se justifica la dominación. Por lo tanto, una representación social legítima del género dicta una demarcación dual con tipificaciones claras de sus tareas, en la que toda transgresión conlleva a la expulsión, por medio también del mismo lenguaje. Es en este espacio en el que funciona el insulto. Se verá entonces cómo es recibida la dominación simbólica por el protagonista y de igual forma cómo es interpretada por el narrador del texto:

Cualquier inclinación hacia lo suave (en su más generoso sentido) era afeminación, y ese supremo interdicto — bendecido repugnantemente por la Iglesia cristiana - tenía y tiene una voz infamante e injuriosa (abyecta) que pretende con increíble crueldad —-bendecida repugnante e históricamente por la Iglesia católica- marcarte para siempre, si no te ocultas o corriges, en un reducto de lo paria, que la Historia terminó, en ocasiones, por volver prestigioso - prestigio que los insultantes ignoraban e ignoran - y ese nombre era y sigue siendo: marica. (Villena, 2006: 50)

La cita anterior es básica para el estudio de la injuria en el texto de Villena, ya que es precisamente el momento en el que el narrador expresa la palabra que causa el daño en él cuando era niño: "marica". De esta forma, es posible ver de qué manera el narrador va organizando el tejido de la narración para explicar el contexto de un niño que debe enfrentarse a la realidad de un colegio donde el machismo es un valor por medio de la exaltación de la virilidad. Por lo tanto, la llegada del insulto se hace evidente y en cierta medida también natural, lo cual 
justifica que haya una mayoría silenciosa que observa el descrédito y no reacciona ante él, para demostrar con su actitud pasiva una aprobación directa.

El protagonista, por tanto, debe enfrentarse al calificativo de marica como una reacción natural ante la amenaza. Esto por varias razones, en primer lugar, no hay una madurez suficiente en el proceso de la conformación de la identidad de género como para hacer una apropiación del término, luego resignificarlo y definirse desde la marginalidad ${ }^{6}$; y, en segundo lugar, el protagonista se encuentra totalmente "dentro del armario", es decir no tiene intenciones de liberarse de la mentira. Por lo cual, el término resulta una desvalorización de la masculinidad que constantemente debe ser demostrada por medio de pruebas y ritos. Las posiciones que el adolescente tome para tratar de contrarrestar la carga de la injuria obedecen a una necesidad de autoprotección y al mismo tiempo constituyen poco a poco y por medio de la repetición constante de la ofensa, una manera que tiene para empezar a definirse desde lo marginal. Por este motivo Eribon (2001) considera que es la injuria el principio de toda identidad gay?

El capítulo del texto de Villena que se dedica especialmente a la injuria se titula: "Aparece una víctima: yo". Desde el inicio, la posición del narrador es la de demostrar en qué medida fue víctima de las circunstancias vividas en el colegio, víctima del machismo acérrimo y además víctima del pensamiento retrógrado de una España poco desarrollada para la época. Además, es necesario notar el carácter centrado en el yo como víctima, característica que puede aparecer con frecuencia en los textos autobiográficos al haber un intento de tomar una posición en la que se capte la benevolencia del lector y haya una identificación entre ambos. En este capítulo hay una mayor introspección, precisamente debido al carácter más íntimo que posee, a diferencia de los demás que se dedican especialmente al contexto colegial. La introspección inicia gracias a una noticia que le recuerda al protagonista su infancia. Se trata de un adolescente que se suicida a causa del acoso sufrido en su colegio, hecho que produce una inmediata identificación y lleva hacia las partes más íntimas del relato.

Es interesante también notar que el autor hace referencia directa al texto de Eribon (2001) que ha sido utilizado en la parte teórica de este apartado, ya que construye sus reflexiones a partir del análisis planteado en Reflexiones sobre la cuestión gay y las implicaciones del discurso injurioso en la identidad:

Didier Eribon ha dicho en un libro en general muy notable, Reflexiones sobre la cuestión gay, que la historia de la condición homosexual empieza con un insulto [...] La palabra abyecta queda grabada en ti como un estigma horrible y deberás, en adelante, intentar convivir con ella. Adelantemos algo: no todos lo logran y la mayoría resulta herida, y la llaga suele ser visible... (Villena, 2006: 47)

El narrador trata de determinar de qué manera iniciaron las ofensas reiteradas en su contra, pero resulta difuso. Sin embargo, está seguro de que 
los primeros tres años fueron los más duros, "cuando los preadolescentes o púberes (ya no niños de doce a catorce años) mezclan a una difusa y cada vez mas irreal inocencia [...] a una brutalidad cerril que el machismo social les acrecienta" (Villena, 2006: 47). Para el protagonista, caer en la cuenta de lo que implicaban estas palabras que se dirigían a él era precisamente comprender su posición marginal. Es decir, a partir de esto pudo tomar conciencia de que su diferencia implicaba el rechazo de los otros y era algo de lo que sería necesario protegerse.

El insulto se podía presentar además de diversas formas, como él mismo lo señala, ya sea el insulto directo — marica — o el "piropo insulto" que consistía en una suerte de halago a través de una comparación con virtudes físicas femeninas, las cuales relacionadas con el cuerpo masculino resultan degradantes desde el punto de vista del machismo. En este proceso, el protagonista empieza a relacionar directamente el colegio con ese sufrimiento que le provocaba, hasta convertir el colegio mismo en una metonimia del insulto y la marginación que debía sufrir:

El colegio era para mí la palabra abyecta y sus consecuencias tenaces, el sitio donde no eres querido, el lugar que te muestra que no tienes otra posibilidad que defenderte, siendo así que yo era un absoluto inepto - acaso por los mimos familiares_ en mi propia defensa que, teóricamente, siempre dependió de otros. (Villena, 2006: 47)

Es necesario preguntarse entonces cuál es la posición que toma el narrador ante el recuerdo de las situaciones dolorosas de la adolescencia, ya que puede parecer un tanto contradictorio su discurso en torno al tema. En primer lugar, afirma que los puede olvidar y los ha olvidado, a pesar de ser este tema recurrente en los otros dos textos mencionados y de afirmar que han sido siempre intentos de dejar atrás una infancia que no ha podido olvidar. En segundo lugar, considera que lo que no puede hacer es perdonar a sus excompañeros, por lo cual llega hasta a maldecirlos: "Para perdonarlos, sin embargo, necesitaría otra vida, o un cambio radical en esta — por el que abogo- pero que aún no ha llegado" (Villena, 2006: 59).

Se observa entonces una necesidad de curación a partir de la palabra, la cual no llega del todo, sino que forma parte de un proceso mayor; en este sentido se explica cómo hay una constante vuelta a la infancia en los libros de carácter autobiográfico del autor, en donde se rememora la manera en que se llega a una conciencia de la marginalidad y el dolor que esto implica. En este punto es donde toma el narrador una posición más política al abogar directamente por el cambio necesario para poder asumir la aceptación de la diferencia; este cambio implicaría una visión distinta de las estructuras de género en donde se vea mayormente la inclusión, en lugar de una estructura dual y cerrada que propone el patriarcado, de manera que la visión queer, en términos de una nueva forma de pensar, se hace más evidente en el texto. 


\section{Conclusiones. Una política estética}

Como hemos podido observar, el texto de memorias Mi colegio de Luis Antonio de Villena, se construye a partir de las características prototípicas de la escritura íntima mediante la identificación clara y directa del nombre del autor con el del protagonista y narrador del relato. No existe ambigüedad en la identificación para cerrar el pacto autobiográfico en términos de Lejeune (1994). De esta manera, tanto los paratextos como las referencias intertextuales confirman una escritura de memorias parciales que intenta centrarse en el relato del dolor causado por la época del colegio del autor.

Es entonces la condición de excluido que prima en la caracterización identitaria a lo largo de la escritura íntima de Villena. Así entonces, cuando el protagonista toma conciencia de su condición de marginal y de excluido, este necesita empezar a crear una forma de protección de sí mismo que le permita funcionar dentro de los marcos de un sistema cerrado y represivo. Empieza entonces a configurar una fachada a partir de la cual pueda justificar, en cierta forma, esa rareza que ven los otros en él y desvíen, al mismo tiempo, la mirada de la identidad sexual. Es posible ver este tipo de actitudes en los capítulos "Las galas del esteta" y "La obsesión sexual", en donde hay una toma de posición respecto de esa diferencia de la que se ha venido hablando con el objetivo de contrarrestar el efecto injurioso de la palabra del otro:

Seamos sinceros en el mar de contradicciones: si la víctima fui yo [...] aquel esteta fui yo también. Es más, creo que - en lo posible, nunca del todoel esteta salvó a la víctima. O casi la salvó. Porque los que disparaban los feroces venablos de la agresión [...] comenzaron a unir, en su magín nacionalcatólico, que la rareza y la singularidad de aquel compañero distinto no venía solo de su posible lado afeminado o femenino, sino también de la disparatada vocación literaria de aquel chiquito — bueno en el fondo-que no se contentaba con una, sino que, - si así pudiera decirse- coleccionaba rarezas. (Villena, 2006: 101)

La necesidad de "coleccionar rarezas" tiene en parte origen en la intención de ocultar una de ellas, por lo cual funcionaba como un escudo que lo protegía y le generaba un cierto respeto de los de su entorno al crear un prestigio social, y la forma para llegar a él la encontró en la literatura, de manera que en los últimos años se dedicaba ya a la escritura poética y a la crítica literaria desde la revista del colegio. Además, reconoce la influencia que ejercieron sobre él personajes de la literatura como Oscar Wilde, Marcel Proust y André Gide, en quienes reconocía de igual forma esa tendencia a la rareza que le podía demostrar que no estaba solo y que la literatura era una importante posibilidad.

La literatura entonces constituyó un espacio importante para el protagonista en la medida en que lo alejaba del oprobio y la injuria en la palabra de los otros, lo cual lo condujo también a expresarse a sí mismo más allá de sus gustos literarios, en la construcción de un personaje particular, de complicada 
definición y sexualmente ambiguo, como manera de protesta y desestabilización de la estructura prototípica patriarcal. La subversión de la imagen de la masculinidad tradicional es un rasgo central en la obra analizada de Villena, ya que explora otras posibles manifestaciones del género en sí mismo y en los textos, lo cual se observa claramente a través de su escritura autobiográfica para completar ese marco subversivo en la palabra que no llegó a concretar en la adolescencia.

\section{Notas}

1 Este colegio se encuentra en la calle Castelló 56, Madrid. Su fundación se dio por la orden de los Marianistas en 1904 y el traslado al edificio actual se realizó en 1921 (datos de http://www.nspilar.com/).

2 De Villena, L. A. (1982). Ante el espejo: memorias de una adolescencia. Barcelona: Argos Bergara. De Villena, L. A. (2004). Patria y sexo. Madrid: Seix Barral.

3 La lectura autobiográfica del texto de Leduc se ha favorecido, según algunos críticos, por la lectura del prefacio escrito por Simone de Beauvoir, en donde recalca la sinceridad de la novelista a partir de sus conocimientos sobre esta lectura. Ver Violette, Catherine (2006).

4 Esta referencia de Stendhal se encuentra en la novela de 1830 llamada Le rouge et le Noir, en palabras del protagonista, Julien. El texto completo es el siguiente:

Quelle garantie peut-elle me donner avec son caractère ? Hélas ! Mon peu de mérite répond à tout. Je manquerai d'élégance dans mes manières, ma façon de parler sera lourde et monotone. Grand Dieu ! Pour quoi suis-je moi ? (Stendhal, 1993: 419).

Georges May (1982) hace referencia a los móviles afectivos para hacer una breve clasificación de las motivaciones que puede tener la escritura autobiográfica, muchas veces explicada por el mismo autor desde textos previos como prólogos o notas. En sus consideraciones se toma en cuenta, por ejemplo, la "simple alegría de vivir -con pluma en mano- de sus años juveniles" (May, 1982: 56-57), o también para otro caso, la necesidad de evadirse del presente angustiante: "si la empresa autobiográfica puede ser engendrada por el deseo de disfrutar de sus recuerdos, también puede serlo por la loca esperanza de detener el curso del tiempo y pretender que vuelva atrás" (May, 1982: 60).

6 Como lo es el caso del término queer que pasa desde el lenguaje de la injuria a denominar todo un movimiento identitario que da voz a los marginados y más allá de eso engloba los estudios culturales respecto del mismo tema. En el caso de España es posible ver la tendencia en teóricos y estudiosos del género como Beatriz Preciado o Javier Sáenz a denominar teorías maricas o bolleras para realizar el mismo proceso de apropiación de términos ofensivos y darles un giro en su uso a partir de la toma de la palabra y la autodefinición. Ver Preciado, Beatriz (2002) y Córdoba, David et al. (2005).

7 Para profundizar sobre el tema del acto de habla performativo como construcción de la identidad a partir de la injuria, además del estudio de Eribon (2001), es necesario ver el análisis y amplio desarrollo que le da a esto Judith Butler (2009) después de 
haberlo planteado en un texto clave para la conformación de la teoría queer: El género en disputa (2001). El texto de 2009 se dedica más específicamente a explicar cómo se plantean teóricamente los actos de habla (término de Austin) como interpelación (término de Althusser), en especial el carácter del lenguaje ofensivo.

\section{Bibliografía}

Alberca, M. (2007). El pacto ambiguo: de la novela autobiográfica a la autoficción. Madrid: Biblioteca Nueva.

(1999) "En las fronteras de la autobiografía”. En: Ledesma Pedraz, Manuela (ed.). II Seminario de escritura autobiográfica. Jaén: Universidad de Jaén.

Bersani, L. (1998). Homos. Buenos Aires: Ediciones Manantial.

Butler, J. (2001). El género en disputa. El feminismo y la subversión de la identidad. México: Editorial Paidós.

(2009). Lenguaje, poder e identidad. Madrid: Editorial Síntesis.

Córdoba, D. et al. (eds.) (2005). Teoría queer. Politicas bolleras, maricas, trans, mestizas. Madrid: Editorial EGALES.

De Villena, L. A. (1982). Ante el espejo: memorias de una adolescencia. Barcelona: Argos Bergara.

(2004). Patria y sexo. Madrid: Seix Barral.

(2006). Mi colegio. Barcelona: Ediciones Península.

Eribon, D. (2001). Reflexiones sobre la cuestión gay. Barcelona: Ediciones Anagrama.

Foster, D. W. (1999). Spanish writers on gay and lesbian themes: a bio-critical sourcebook. London: Greenwood Press.

(2000). Producción cultural e identidades homoeróticas. San José: Editorial Universidad de Costa Rica.

Kosofsky Segdwick, E. (1990). Epistemology of the closet. California: University of California Press.

Lejeune, P. (1994). El pacto autobiográfico y otros estudios. Madrid: MegazulEndymion.

(1986). Moi aussi. Paris: Editions du Seuil.

May, G. (1982). La autobiografía. Fondo de Cultura Económica.

Miraux, J. P. (2005). La autobiografía: las escrituras del yo. Buenos Aires: Nueva Visión.

Pérez-Sánchez, G. (2007). Queer Transitions in Contemporary Spanish Culture. From Franco to la Movida. New York: State University of New York Press.

Pozuelo Yvancos, J. M. (2005). De la autobiografía: teoría y estilos. Barcelona: Crítica.

Preciado, B. (2002). Manifiesto contra-sexual. Madrid: Editorial Opera Prima.

Puertas Moya, F. E. (2004). Aproximación semiótica a los rasgos generales de la escritura autobiográfica. Logroño: Universidad de La Rioja.

(2004). Los orígenes de la escritura autobiográfica: género y modernidad. Logroño: Serva. 
et al. (eds.) (2004). El temblor ubicuo: (panorama de escrituras autobiográficas). Logroño: Seminario de Estudios sobre Relatos de Vida y Autobiografías. Universidad de La Rioja.

Romera Castillo, J. (1981) "La literatura: signo autobiográfico. El escritor, signo referencial de su escritura” en Romera Castillo, José (ed.), La literatura como signo. Ediciones Playor.

(2006). De primera mano: sobre escritura autobiográfica en España (siglo $X X)$. Madrid: Visor Libros.

Stendhal (1993). Le rouge et le Noir. Chronique de 1830. París: Maxi-Poches.

Violette, C. (2006). "Violette Leduc, dès Ravages à La Bâtarde " [En línea] Consultado el 19 de enero de 2014 : http://www.item.ens.fr/index.php?id=13806. 
